\title{
Land-use Assessment and its Influence on Spatial Distribution of Rainfall Erosivity: Case Study of Cameron Highlands Malaysia
}

\author{
Muhammad Raza UI Mustafa ${ }^{1,2}$, Abdulkadir Taofeeq Sholagberu ${ }^{1,3^{*}}$, \\ Muhammad Asyraf Syazwan', Khamaruzaman Wan Yusof', \\ Ahmad Mustafa Hashim'1, Abdurrasheed S. Abdurrasheed ${ }^{1}$ \\ 1 Department of Civil and Environmental Engineering, Universiti Teknologi Petronas, 32610 Seri Iskandar \\ Perak, Malaysia \\ 2 Centre for Urban Resource Sustainability, Institute of Self-Sustainable Building, Universiti Teknologi Petronas, \\ 32610 Seri Iskandar, Perak, Malaysia \\ 3 Department of Water Resources and Environmental Engineering, University of Ilorin, PMB 1515 Ilorin, Nigeria \\ * Corresponding author's e-mail: abdulkadir.ts@unilorin.edu.ng
}

\begin{abstract}
Over the years, Cameron Highlands have witnessed extensive land-use and land-cover (LULC) changes due to the massive agricultural and urbanization activities. This significantly contributed to the erosion problems in the area. Rainfall erosivity that measures the aggressiveness of raindrop in triggering soil erosion is one of its major components that could be influenced by the LULC changes in watersheds. However, the research relating to theLULC changes with the erosivity especially in the complex landscape is scarce. Hence, this study applies geographic information system (GIS) and remote sensing techniques to assess the LULC changes and their influence on the rainfall erosivity distribution in mountainous watershed of Cameron Highlands. Four Landsat images and the rainfall data from the period of thirty years were analysed for the development of LULC and erosivity maps respectively in ArcGIS environment. The study showed that the study area experienced immense land-use changes especially in agriculture and urbanization which affected the erosivity distribution. The LULC change for agriculture increased linearly in the last 30 years from $7.9 \%$ in 1986 to almost $16.4 \%$ in 2016 . The results showed that urban development increased from $5.1 \%$ in 1986 to $11.4 \%$ in 2016 . The increasing urbanization trend was targeted to meet up with tourism requirement in Cameron Highlands. However, forest class declined tremendously due to the exploration of land for agriculture practice and other various types of development. Watershed managers and other stakeholders should find this study beneficial in tackling erosion and its associated ecological challenges.
\end{abstract}

Keywords: Land-use, land-cover, erosivity, Cameron Highlands, GIS

\section{INTRODUCTION}

Land-use is an important component with socioeconomic and cultural values for the sustenance of biodiversity and ecosystem activities. Land-covers are the observed biophysical covers on the earth's surface (Di Gregorio, 2005) and the socio-economic interpretation of the activities taking place on land is the land-use of such locality (Straume, 2014). Both land-use and land-cover are often used interchangeably in several environmental studies. However, constant changing in the land-use pattern has been reported as the primary cause of land-cover change (Cegielska et al., 2018). Land-use/land-cover (LULC) is of great significance and a central component of the current strategies in monitoring, evaluating, protecting and planning of natural resources for sustainable management. According to Zubair (2006), the LULC pattern of any locality is a product of its natural and socio-economic factors and their level of utilization by human in time and space. The growth in population leading to increasing in human activities could result in soil erosion, 
global warming, and pollution that are very harmful to the environment (Cegielska et al., 2018). Land-cover classification is one of the most studied topics in remote sensing, as land-cover maps provide the basis for many applications in modelling of carbon budgets, management of forests, and estimation of crop yield (Zhu and Woodcock, 2014). The authors also highlighted that landcover impacted on the energy balance, carbon budget, and hydrological cycle relating to albedo, emissivity, roughness, photosynthetic capacity, and transpiration. The reports of past research showed that only few landscapes of the earth still remain in their natural state (Zubair, 2006). This makes the resources a scarce due to the extensive agricultural and demographic pressures. Urban development, forest harvesting, land degradation through desertification and agricultural practices are the major human-driven land-use changes that considerably alter natural landscapes. However, the land-use change is also being influenced by some various natural phenomena such as topography, distribution pattern of vegetation, water, proneness to hazards zones, proximity to required resources, etc (Abdulkadir et al., 2017). IPCC (2000) recognized land-use as an important component of global change. It was also reported as an important factor in determining the climate of a region through both biophysical and biogeochemical processes (Cegielska et al., 2018).

Remote sensing data with varying spatial resolutions have been applied for mapping and monitoring of LULC changes in the urban environment. The availability of computers and the advances in remote sensing techniques and computing technology, have aided the application of these data in the LULC studies focusing on the urban and agglomeration growth processes and the areas threatened by human pressure (Cegielska et al., 2018). It has been established that the LULC distribution patterns have great influence on the occurrence and spatial distribution of some land degradation features. Soil erosion as one of such land degradations is related to several other factors which include rainfall processes, landuse, soil, terrain, and topography (Zhang et al., 2017). Universal soil loss equation (USLE) developed by Wischmeier and Smith (1965) is one of the most popular models for the estimation of the average annual rate soil loss on a longterm basis. It basically involves parameterization of several factors such as rainfall erosivity factor-R (MJ $\mathrm{mm} / \mathrm{ha} / \mathrm{yr})$, soil erodibility factor-
$\mathrm{K}$ (t ha $\mathrm{yr} / \mathrm{MJ} / \mathrm{mm}$ ), slope length factor-L, slope steepness factor-S, cover and management factor$\mathrm{C}$ and the supporting practices factor-P (MingHsi and Huan-Hsuan, 2015). A revised version of the USLE model (RUSLE) is a widely used empirical method in temperate regions whose $\mathrm{R}$-factor, is the summation of all erosive events during a one year period (Renard et al., 1997). Despite being originally applied at plot scale, it is now being applied on catchments in a wide set of environments, including semi-natural ecosystems and mountainous areas (Stanchi et al., 2015). Erosivity being one of the major biophysical components of RUSLE could be influenced by LULC of any watershed. It measures the aggressiveness of raindrop in detaching soil particles, thereby triggering soil erosion. However, detailed research relating to the land-cover changes with the erosivity nature especially in the complex landscape witnessing rapid development is scarce. Hence, this study aimed to assess the LULC changes and their influence on the rainfall erosivity distribution in mountainous watershed across Cameron Highlands Malaysia using geographic information system and remote sensing techniques.

\section{Description of Study Area}

Cameron Highland, located in $4^{\circ} 19^{\prime}-4^{\circ} 37^{\prime} \mathrm{N}$ and $101^{\circ} 21^{\prime}-101^{\circ} 30^{\prime} \mathrm{E}$, is among Malaysia's most extensive hilly region with a total landmass of about 71.21 ha, having almost $75 \%$ of the highlands approximately 1,000 metres above sea level. The region is witnessing high rate of urbanization and population growth due to tourism activities. The increasing farming and logging activities on hillslopes are due to the urges to increase the productivities and income. These have inevitably resulted in rapid land-use changes, exposing soil surfaces to erosion which led to sedimentation of waterways, triggering landslides, flash floods, deterioration of water quality, etc. Moreover, excessive tillage crop method practiced on the highlands caused soil structure breakdown and increased soil erosion rates (Mohd et al., 2010). In a report published by World Wide Fund for Nature (World Wildlife Fund Malaysia, 2002), about $81 \%$ of the watershed area have high erosion risk due to its nature and increased human activities. All these factors have increased the erosion rates and sediment delivery to water bodies within the catchment vicinity. Abdullah (2016) reported that about $45 \%$ of agriculture lands in the area have more than $25^{\circ}$ slope with runoff causing erosion 
and massive river siltation. More so, the presence of weathered underlying rocks (Barrow et al., 2005), topography and heavy rainfall make the region highly prone to erosion and landslide that threatens the development on the highlands (Pradhan et al., 2010). Meteorological records showed that the area received high average rainfall ranging between 2500 and $3000 \mathrm{~mm}$ annually (Gasim et al., 2009) with high intensity that increases the aggressiveness of raindrops to trigger soil erosion. Rapid LULC changes in Cameron Highlands altered the natural ecosystem over the area. In a study by Raj (2002), land-use changes in the area occur mainly on tea estates and orchards at the expense of forests for the years 1947 to 1974. Up till today, there has been further expansion in commercial area, residential or urban centres while the tea estates and orchards reduced. This phenomenon resulted in triggering erosion with on- and off-site impacts.

\section{MATERIALS AND METHODS}

Two basic components of this research are development and the analysis of LULC and erosivity maps for Cameron Highlands. The former was developed from the Landsat data retrieved from the archive of United States Geological Survey (USGS) website while the latter were from the rainfall record obtained from Malaysia Department of Irrigation and Drainage (DID). ArcGIS ${ }^{\circledR}$ 10 was used for the pre-processing and processing of the data for the development of spatial distribution maps for LULC and erosivity maps for Cameron Highlands.

\section{Rainfall Erosivity}

The rainfall erosivity factor is defined as the erosive force from raindrops that detached and washed away soil particles. Raindrops are the erosive agents with kinetic energy that instigate the disintegration and movement of soil particles. Due to the scarcity of field measurements of the kinetic energy of rainfall both in time and space, several studies were conducted to assess the relationship between rainfall characteristics and soil detachment (Meusburger et al., 2012). However, computation of $\mathrm{R}$-factor for a particular watershed requires high temporal rainfall resolution (pluviograph) data with a maximum of 30-minutes intensities for at least 20 years (Meusburger et al., 2012). However, precipitation time-series with such temporal resolution is rarely available in many parts of the world (Abdulkadir et al., 2016). Thus, various simplified models were proposed and implemented for estimating R-factor using precipitation volume (daily, monthly or yearly data) instead of intensity (Meusburger et al., 2012). Bols (1978) proposed an expression for estimating erosivity value based on the empirical study in Indonesia, as shown in Equation 1. This solution was adopted in Malaysia, owing to its similarity in climatic conditions and unavailability of high resolution data. The rainfall data was obtained from DID for seventeen rainfall stations within and around the study area. However, some rainfall data was missing and was fixed using linear interpolation technique. The rainfall record of 1986 only was implemented for the estimation of erosivity values for all the stations using Equation 1. The results obtained were used for the development of rainfall erosivity map in ArcGIS using the kriging method of Geostatistical Analyst toolbar. Then, the erosivity map was re-projected into coordinate system of WGS 1984/UTM Zone 47o N applicable to the study area. Similarly, the procedures were repeated for rainfall record of 1986, 1987-1996, 1997-2006 and 2007-2016 for the computation and development of erosivity maps.

$$
R=\frac{2.5 P^{2}}{100(0.073 P+0.73)}
$$

where: $P=$ Annual rainfall $(\mathrm{mm})$

\section{Landsat Imageries and Data Processing}

In order to develop the LULC maps for Cameron Highlands to analyse its impact on erosivity distribution, Landsat data were used. Raw satellite data were required to develop the LULC map and assess the decadal land-use changes that took place in the last three decades in the study area. The satellite data used were retrieved for the years 1986, 1996, 2006 and 2016 from USGS Earth Resource Observation Systems Data Center for the location (Row/Path: 57/127) on a relatively clear day with less cloud cover. The raw Landsat data were then pre-processed in ArcGIS ${ }^{\circledR}$ for atmospheric and radiometric corrections. Then, Landsat images were processed for LULC classification into four major classes which are agriculture, forest, urban and water. Supervised classification training algorithm with maximum likelihood in ArcGIS ${ }^{\circledR}$ was used to ensure successful analyses 
with higher accuracy output. A sufficient number of training points was selected for each land-use class for the training in the ArcGIS environment. Thus, the resultant LULC maps for the years 1986, 1996, 2006 and 2016 were developed for the study area. The accuracies of LULC classification for each year were evaluated to ascertain the applicability of the results for further analyses. These LULC maps were correlated with the respective erosivity maps of 1986, 1987-1996, 1997-2006 and 2007-2016. Then, layers of rainfall erosivity and the corresponding LULC maps were analysed for the assessment of impacts of LULC changes on erosivity pattern in Cameron Highlands. This was achieved by overlaying these maps over one another for pixel-to-pixel analysis of the relationship between LULC and erosivity.

\section{RESULTS AND DISCUSSION}

This study developed and evaluated the decadal LULC changes and rainfall erosivity maps for the period of three decades, starting from the years 1986 to 2016 . The rainfall record obtained for this period was used for the analysis of spatial distribution and variability of erosivity in the study area. The temporal analysis highlighting monthly variability pattern of R-factor for the study area is shown in Figure 1. Comparing with the rainfall pattern, the least and peak R-factors estimates occurred in the months of February and November having 52.79 and 512.26 MJ mm $\mathrm{ha}^{-1} \mathrm{~h}^{-1}$ year ${ }^{-1}$ respectively. The result showed that the peak rainfall cycle is the most critical period of higher R-factor in the watershed of Cameron Highlands. It was observed that the erosive power starts to increase from the month of January through April, before starting to fall to the lowest value in the month of June. Then, it started increasing again from July until it reached another peak in the peak rainfall cycle. The fluctuation in $\mathrm{R}$-factor trends may be attributed to the temporal variability in the rainfall amount and intensity which result in increasing the aggressiveness of raindrops to trigger erosion in Cameron Highlands. The higher erosivity was observed to be caused by higher amount, intensity and kinetic energy of the rain, especially in the tropical zones.

The LULC of Cameron Highlands was developed for the years 1986, 1996, 2006 and 2016 and classified into four prominent land-use classes which are urban settlement, forest, agriculture, and water. Figure 2 presents the developed LULC map. The study showed that Cameron highlands were heavily forested, occupying $87 \%$ in the year 1986 being the initial stage of development. Human activities, i.e. farming and urbanization were at relatively low, occupying $7.9 \%$ and $5.1 \%$, respectively, as presented in Table 1. The spatial distribution of rainfall erosivity for the 1986 is presented in Figure 3. The analysis of this erosivity map showed that the western (especially northwest) region of Cameron Highlands experienced higher rainfall erosivity compared to the eastern region. This was because the western region was occupied by urban and agricultural activities which expose the land surface to direct rain events. As a result, these human-environment interactions aided the aggressiveness of raindrops. However, the eastern region has heavy forest cover with less human activities. On the basis of the rainfall erosivity and land-use maps of 1986, it can be inferred that the land-use changes were not too intense and the rainfall erosivity factors in each of the land-use classes were also relatively small. The spatial variation in the R-factor obtained from locations to locations was suggested

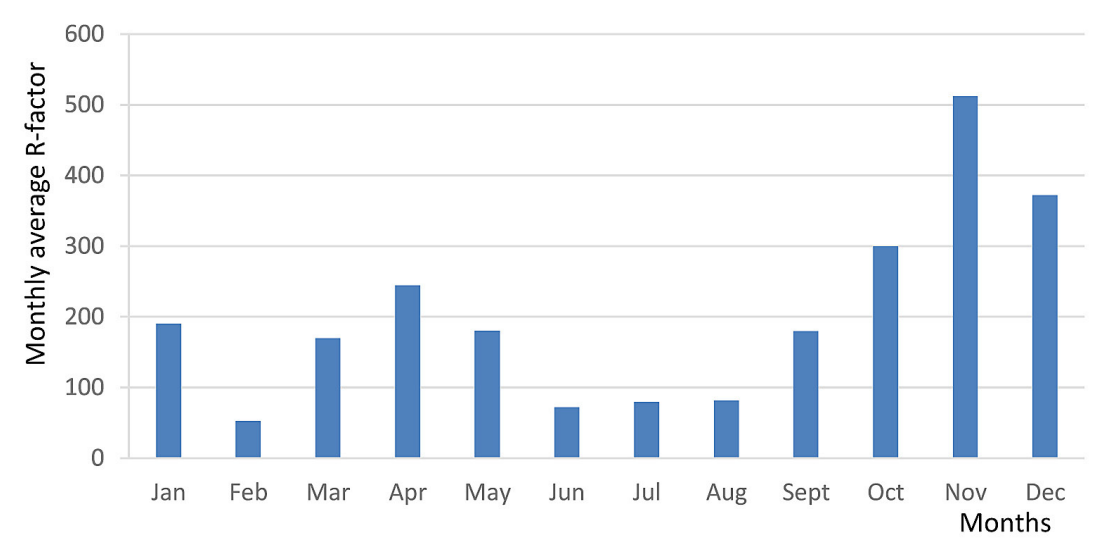

Figure 1. Monthly temporal variability of R-factor 


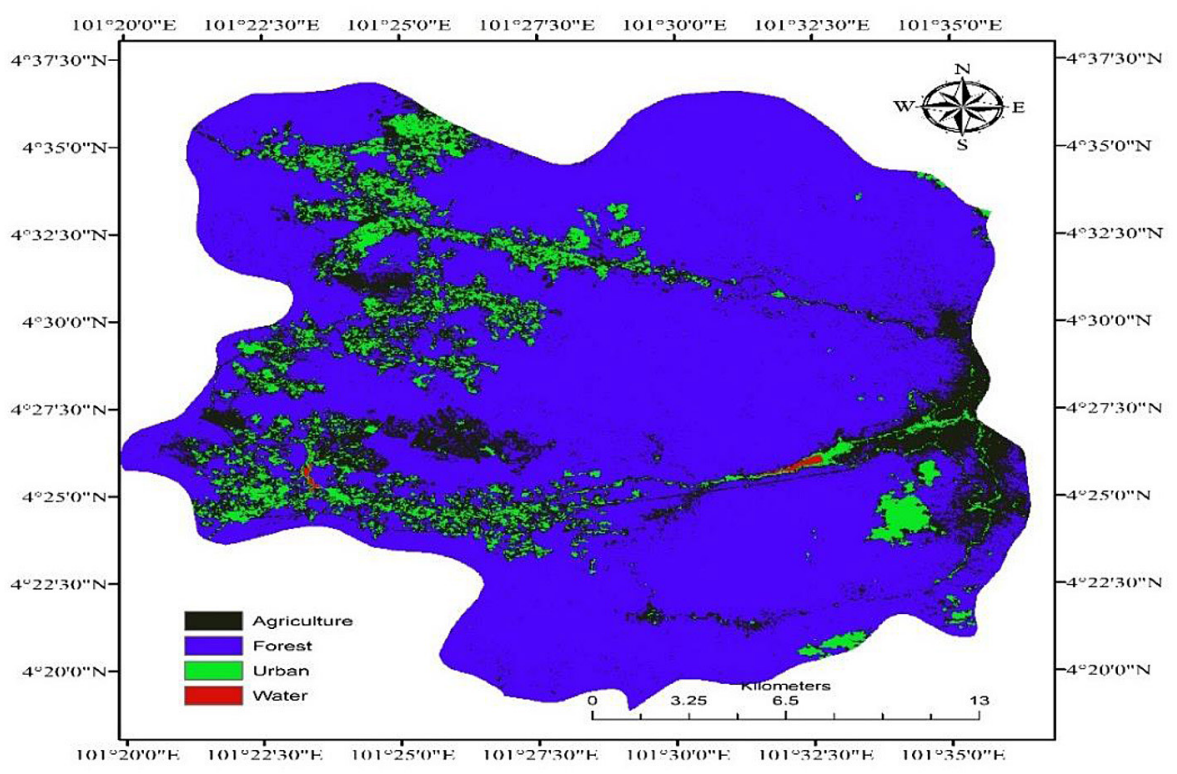

Figure 2. Land-use/land-cover map for the year 1986

Table 1. LULC classification accuracies for each year

\begin{tabular}{|c|c|}
\hline Years & \% Classification accuracies \\
\hline 1986 & 85.1 \\
\hline 1996 & 88.2 \\
\hline 2006 & 80.1 \\
\hline 2016 & 86.9 \\
\hline
\end{tabular}

to have caused by elevation differences in the watershed that increases the aggressiveness of the runoff generated rainfall events.

Subsequently, the Landsat data for the year 1996 was implemented for the development of the LULC maps while rainfall records of 1987 to 1996 were used for the erosivity maps. Similarly, the LULC maps for the years 2006 and 2016 and erosivity maps for the years 1997-2006 and 2007-2016 were developed and analysed. The overall accuracies of the Landsat-derived LULC maps developed each year were assessed and presented in Table 1. The results of classification accuracies were found to be acceptable for all the years. Tables 2 and 3 present the results obtained for the analyses of the LULC and erosivity maps for the years 1986 and 1996, respectively. The analysis of the results obtained for these years showed that the forest coverage decreased from $87.0 \%$ to $82.0 \%$ while the agricultural activities increased significantly from $7.9 \%$ in 1986 to $11.2 \%$ in 1996. Similarly, the urban development coverage slightly increased to $6.6 \%$ from $5.1 \%$ and water body also increased slightly to $0.09 \%$. On the other hand, the R-factor in 1996 was relatively huge compared to what was obtained in the year 1986. This might due to the increase in rainfall intensity and amount, together with the intensive changes in land-use pattern through humanenvironment interactions.

Further analyses of the LULC for the year 2006 and its corresponding erosivity distribution, as presented in Table 4, showed that Cameron Highlands witnessed a greater increase in the urbanization rate than in agriculture, when compared with that of 1996. It was because of rapid development occurred even on the highlands region, especially construction of more housing estates due to increasing rate of tourism development, among others. On the contrary, the forest land-use shows a declining trend from 1986 with the area occupied by water remain almost constant. The forest land-use class had the highest average erosivity value among other classes. In terms of spatial distribution, the study showed that the southwest regions had higher R-factor values due to uneven distribution of human activities across the watershed. It was also observed that the forested regions have relatively smaller $\mathrm{R}$-factor values. This is because higher vegetation index from forest provides protection to earth surface, which lessens the aggressiveness of raindrops despite higher rainfall intensity.

Table 5 presents the results obtained for the year 2016. An increasing trend in both agriculture and urban developments were observed, resulting in tremendous decline in the forest volume in Cameron Highlands. This is because massive agriculture practice is taking place on the highlands with different horticultures by local farmers 


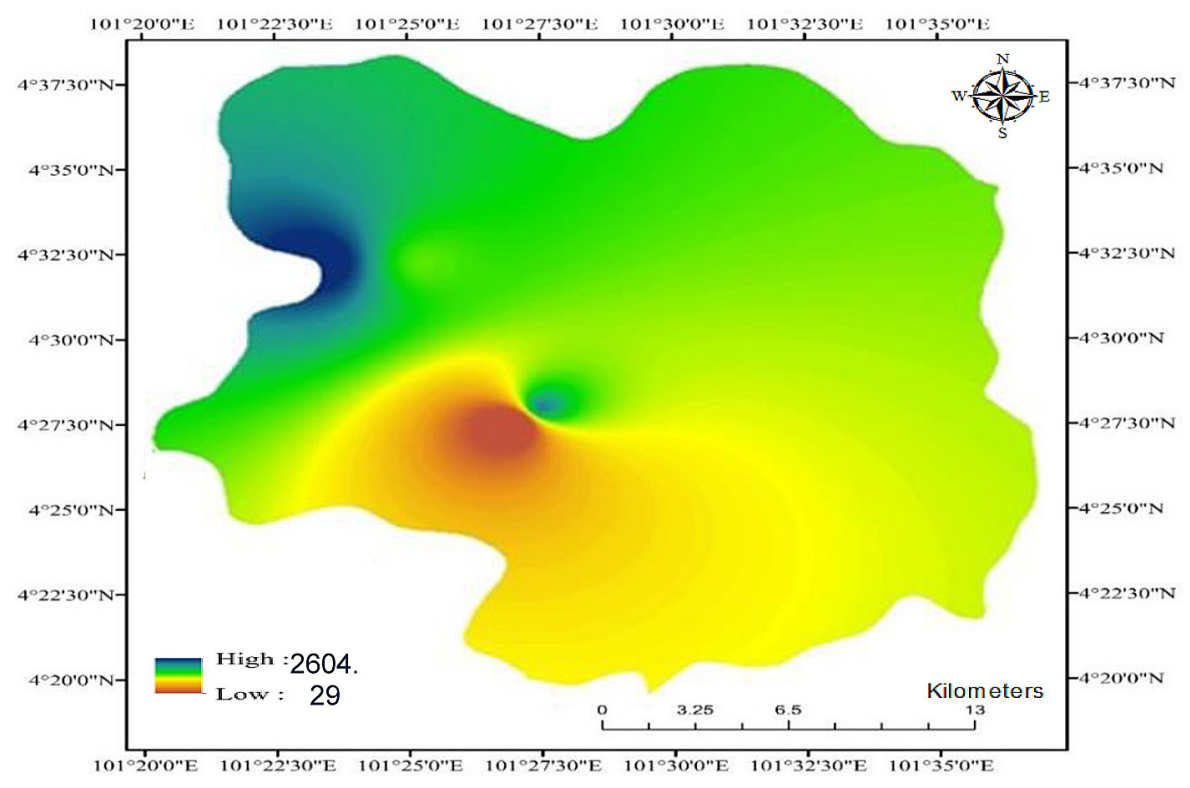

Figure 3. Rainfall erosivity map for the year 1986

to boost their productivities. The decline in forest is also traceable to the increasing rate of urbanization to meet up with the facilities requirement of tourists due to the growing rate of tourism activities in the study area. The study revealed that the highest average R-factor value was observed in the urban land-use class contrary to the result obtained for 2006. The results showed that as the LULC changes, the erosivity distribution also varies in response to the changes. This indicates how land-use influences the rainfall erosivity, because human activities in the watershed remove the protective layer of the earth that often dampens the energy of raindrops. Thus, rapid land-use changes experienced over a 30-year period of the study results in higher rainfall erosivity, which eventually contributed to the soil erosion problems in Cameron Highlands.

\section{CONCLUSION}

Land-use is a crucial factor necessary for sustenance of biodiversity and ecosystem services with socioeconomic values. The current studies evaluated the trend of the land-use change pattern and spatial distribution of rainfall erosivity over the period of three decades in Cameron Highlands Malaysia to understand their relationship. Geospatial technology was adopted for the assessment of the LULC changes as well as development of the LULC map and the erosivity maps.

Table 2. Land-use map with corresponding 1986 R-factor

\begin{tabular}{|c|c|c|c|c|c|}
\hline \multirow{2}{*}{ LULC Class } & \multirow{2}{*}{ Area occupied $\left(\mathrm{km}^{2}\right)$} & \multirow{2}{*}{$\%$ Area } & \multicolumn{3}{|c|}{ R-factor $\left(\mathrm{MJ} \mathrm{mm} \mathrm{ha}^{-1} \mathrm{~h}^{-1}\right.$ year } \\
& & & Maximum & Minimum & Average \\
\hline Agriculture & 56.2 & 7.9 & 709.22 & 678.75 & 699.33 \\
\hline Forest & 615.6 & 87.0 & 699.11 & 631.26 & 660.94 \\
\hline Urban & 36.2 & 5.1 & 721.32 & 631.26 & 674.11 \\
\hline Water & 0.34 & 0.05 & 701.45 & 692.98 & 699.33 \\
\hline
\end{tabular}

Table 3. Land-use map data (1996) with corresponding R-factor for the year 1987-1996

\begin{tabular}{|c|c|c|c|c|c|}
\hline \multirow{2}{*}{ LULC Class } & \multirow{2}{*}{ Area occupied $\left(\mathrm{km}^{2}\right)$} & \multirow{2}{*}{$\%$ Area } & \multicolumn{3}{|c|}{ R-factor $\left(\mathrm{MJ} \mathrm{mm} \mathrm{ha}^{-1} \mathrm{~h}^{-1}\right.$ year } \\
& & & Maximum & Minimum & Average \\
\hline Agriculture & 79.41 & 11.2 & 799.31 & 707.56 & 739.28 \\
\hline Forest & 584.92 & 82.0 & 812.08 & 696.92 & 746.62 \\
\hline Urban & 43.32 & 6.6 & 775.53 & 703.99 & 737.81 \\
\hline Water & 0.61 & 0.09 & 751.07 & 743.33 & 746.16 \\
\hline
\end{tabular}


Table 4. Land-use map data (2006) with corresponding R-factor for the year 1997-2006

\begin{tabular}{|c|c|c|c|c|c|}
\hline \multirow{2}{*}{ LULC Class } & \multirow{2}{*}{ Area occupied $\left(\mathrm{km}^{2}\right)$} & \multirow{2}{*}{ \% Area } & \multicolumn{3}{|c|}{ R-factor $\left(\mathrm{MJ} \mathrm{mm} \mathrm{ha}^{-1} \mathrm{~h}^{-1} \mathrm{year}^{-1}\right.$ ) } \\
\cline { 4 - 6 } & & & Maximum & Minimum & Average \\
\hline Agriculture & 94.85 & 13.4 & 859.86 & 691.59 & 750.75 \\
\hline Forest & 542.91 & 76.6 & 841.02 & 694.77 & 754.68 \\
\hline Urban & 69.89 & 9.8 & 814.26 & 693.56 & 751.18 \\
\hline Water & 0.70 & 0.09 & 856.68 & 719.32 & 746.44 \\
\hline
\end{tabular}

Table 5. Land-use map data (2016) with corresponding R-factor for the year 2007-2016

\begin{tabular}{|c|c|c|c|c|c|}
\hline \multirow{2}{*}{ LULC Class } & \multirow{2}{*}{ Area occupied $\left(\mathrm{km}^{2}\right)$} & \multirow{2}{*}{ \% Area } & \multicolumn{3}{|c|}{ R-factor $\left(\mathrm{MJ} \mathrm{mm} \mathrm{ha}^{-1} \mathrm{~h}^{-1} \mathrm{year}^{-1}\right)$} \\
\cline { 4 - 6 } & & 16.4 & 860.75 & 684.70 & 748.44 \\
\hline Agriculture & 116.50 & 72.1 & 868.30 & 679.55 & 745.18 \\
\hline Forest & 510.60 & 11.4 & 870.50 & 685.08 & 758.94 \\
\hline Urban & 80.50 & 0.09 & 856.68 & 719.32 & 756.44 \\
\hline Water & 0.70 & \multicolumn{4}{|c}{} \\
\hline
\end{tabular}

The study showed that Cameron Highlands had undergone massive land-use changes during the study years, especially in agriculture and urbanization, which affected the erosivity distribution. The LULC change for agriculture increased linearly for the last 30 years from $7.9 \%$ in 1986 to almost $16.4 \%$ in 2016 . This highlights the growing rate of tea, flowers and temperate vegetables production in Cameron Highlands. The study showed that urban development was the second highest land-use class, since urban development often occurs gradually. This increased from 5.1\% in 1986 to $11.4 \%$ in 2016 . The increasing urban trend was indeed to meet up with tourism requirement in Cameron Highlands. Nonetheless, the forest class experienced a great decline in area, as a result of the land usage for agricultural practices and various types of urban development. This trend is expected to continue until major urbanisation takes place. In sum, the high rainfall erosivity was found to be associated with rapid landuse changes during the study period of 30 years, which in turn escalate the soil erosion problems in Cameron Highlands. This study should be helpful to the watershed managers and other necessary stakeholders in tackling erosion and its associated ecological problems.

\section{Acknowledgements}

This study was supported by the Universiti Teknologi PETRONAS (UTP), Malaysia under 2016 URIF Grant with cost centre: 0153AA-G04. The second author would like to thank UTP for the provision of Graduate Assistance Scheme.

\section{REFERENCES}

1. Abdulkadir, T.S., Muhammad, M.R., Khamaruzaman, W.Y. and Ahmad, H.M., 2017. Geostatistical based susceptibility mapping of soil erosion and optimization of its causative factors: A conceptual framework. Journal of Engineering Science and Technology, 12(11): 2880-2895.

2. Abdulkadir, T.S., Mustafa, M.R., Khamaruzaman, Y.W. and Hashim, A.M., 2016. Evaluation of rainfall-runoff erosivity factor for Cameron Highlands, Pahang, Malaysia. Journal of Ecological Engineering, 17(3): 1-8.

3. Abdullah, J., 2016. Highlands developments in Malaysia, Globalization and Marginalization in Mountain Regions. Springer, pp. 147-156.

4. Barrow, C., Clifton, J., Chan, N. and Tan, Y., 2005. Sustainable development in Cameron highlands, Malaysia. Malaysian Journal of Environmental Management, 6: 41-57.

5. Bols, P., 1978. The Is-erodent Map of Java and Madura. In: B.T.A.P. ATA (Editor). Soil Research Institute, Bogor, pp. 105.

6. Cegielska, K., Noszczyk, T., Kukulska, A., Szylar, M., Hernik, J., Dixon-Gough, R., Jombach, S., Valánszki, I. and Kovács, K.F., 2018. Land use and land cover changes in post-socialist countries: Some observations from Hungary and Poland. Land Use Policy, 78: 1-18.

7. Di Gregorio, A., 2005. Land Cover Classification System: Classification Concepts and User Manual, Food and Agriculture Organization of the United Nations, Rome.

8. Gasim, M.B., Surif, S., Toriman, M.E., Rahim, S.A., Elfithri, R. and Lun, P.I., 2009. Land-use change and climate-change patterns of the Cameron Highlands, Pahang, Malaysia. The Arab World 
Geographer, 12(1-2): 51-61.

9. IPCC, 2000. Special report on land use, land-use change, and forestry. Cambridge University Press, Cambridge, UK.

10. Meusburger, K., Steel, A., Panagos, P., Montanarella, L. and Alewell, C., 2012. Spatial and temporal variability of rainfall erosivity factor for Switzerland. Hydrol. Earth Syst. Sci., 16: 167-177.

11. Ming-Hsi, L. and Huan-Hsuan, L., 2015. Evaluation of annual rainfall erosivity index based on daily, monthly, and annual precipitation data of rainfall station. International Journal of Distributed Sensor Networks, 11(6): 214708.

12. Mohd, E.T., Karim, O.A., Mokhtar, M., Gazim, M.B. and Abdullah, M.P., 2010. Use of InfoWork RS in modeling the impact of urbanisation on sediment yield in Cameron Highlands Malaysia. Nat Sci, 8(2): 67-73.

13. Pradhan, B., Oh, H.-J. and Buchroithner, M., 2010. Weights-of-evidence model applied to landslide susceptibility mapping in a tropical hilly area. Geomatics, Natural Hazards and Risk, 1(3): 199-223.

14. Raj, J.K., 2002. Land use changes, soil erosion and decreased base flow of rivers at Cameron Highlands, Peninsular Malaysia, Geological Society of Malaysia Annual Geological Conference, Malaysia.

15. Renard, K.G., Foster, G.R. and Weesies, G.A., 1997. Predicting soil erosion by water: a guide to conservation planning with the revised univer- sal soil loss equation (RUSLE), 703. Agriculture Handbook, USDA-ARS, 404 pp.

16. Stanchi, S., Falsone, G. and Bonifacio, E., 2015. Soil aggregation, erodibility, and erosion rates in mountain soils (NW Alps, Italy). Solid Earth, 6: 403-414.

17. Straume, K., 2014. The social construction of a land cover map and its implications for Geographical Information Systems (GIS) as a management tool. Land Use Policy, 39: 44-53.

18. Wischmeier, W.H. and Smith, D.D., 1965. Predicting rainfall erosion losses from cropland east of the rocky mountains, Handbook No. 282, USDA, Washington DC.

19. World Wildlife Fund Malaysia, 2002. Community and non-governmental organisation (NGO) partnership in highland catchment management in Malaysia.

20. Zhang, S., Fan, W., Li, Y. and Yi, Y., 2017. The influence of changes in land use and landscape patterns on soil erosion in a watershed. Science of the Total Environment, 574: 34-45.

21. Zhu, Z. and Woodcock, C.E., 2014. Continuous change detection and classification of land cover using all available Landsat data. Remote sensing of Environment, 144: 152-171.

22. Zubair, A.O., 2006. Change detection in land use and Land cover using remote sensing data and GIS: a case study of Ilorin and its environs in Kwara State, University of Ibadan, Nigeria. 